\title{
The present-day condition of water resources in Belarus
}

\author{
Alexander A. Volchek ${ }^{1}$, Ivan Kirvel ${ }^{2}$, Sergey Parfomuk ${ }^{1}$, Roza Makhambetova ${ }^{3}$ \\ ${ }^{1}$ Brest State Technical University, Moskovskaya 267, Brest 224017, Belarus, e-mail: e-mail: volchak@tut.by \\ ${ }^{2}$ Pomeranian University in Slupsk, Partyzantów 27, 76-200 Slupsk, Poland, e-mail: kirviel@yandex.by \\ ${ }^{3}$ Sh. Esenov Caspian State University of Technologies and Engineering, Akaty 130000, Kazakhstan, e-mail: makhambetova.poza@yandex.kz
}

\begin{abstract}
The optimal number of hydrological monitoring stations for the annual values, the maximum spring, the minimum summerautumn and the minimum winter river runoff in Belarus is determined. The research on optimization of the hydrological network of Belarus led to a conclusion about the optimum number of hydrological stations in the country, but in the case of observing the values of the annual runoff, the number of the existing plants is the minimum necessary, and reducing their number is inadmissible. On the basis of trends in air temperature changes, precipitation and humidity deficits from 1985 to 2009, the forecasts of these parameters are prepared until 2020. Taking into account the models of climatic parameter change, a possible change in the water regime of the rivers in the future is investigated.
\end{abstract}

Key words: river runoff, water regime, hydrological station, Belarus.

\section{Introduction}

Recently on the territory of Belarus a decrease in hydrological stations designed to collect information on the water bodies of the country has been observed. There are several reasons for the closure of stations: reduced funding, the failure of gauging equipment, and the fact that a satisfactory hydrological study of the territory has been achieved. In relation to climate change and increasing human pressure on water bodies, there appears a necessity to optimize the existing regime of the hydrological network. In addition, today the world is increasingly observing abnormal natural phenomena caused by climate change in the second half of the $20^{\text {th }}$ century and the beginning of the $21^{\text {st }}$ century. The need for a predictive environmental study for Belarus derives from the needs of modern state policy (Loginov 2003). During the period 19072006, the overall warming of the Earth was on average $0.74^{\circ} \mathrm{C}$ (Bedritskiy et al. 2008). Particularly sensitive to fluctuations in climate parameters are water resources, the quality and quantity of which vary from year to year with increasing anthropogenic pressure.

In this paper we attempt to determine the optimal number of stations for observing different types of river runoff in Belarus and identify trends in the transformation of climatic parameters and execute forecast changes in the water regime of the rivers of Belarus in the future.

\section{Materials and Methods}

The research is based on the method of optimizing the hydrological network (Karasev 1968). The method relies on the definition of the three criteria that influence the optimal number of stations for observing the runoff.

The first criterion is a criterion of representativeness $F_{\text {repr }}$. This criterion follows from the condition of zoning changes in the runoff (Kovalenko and Pivovarova 2000). Thus, a representative test $F_{r e p r}$ limits $F_{\text {opt }}$ - the optimal area per one hydrological station, from below, i.e. $F_{\text {repr }}<F_{\text {opt }}$.

The second criterion is the gradient criterion $F_{\text {grad }}$ that is determined by the following formula (Karasev 1968):

$$
F_{\text {grad }} \geq \frac{8 \sigma_{0}^{2}}{(\operatorname{grad} Y)^{2}} Y_{a v}^{2},
$$

where: $\sigma_{0}$ - error in determining the rate of runoff; $\operatorname{grad} Y$ - runoff gradient; $Y_{a v}$ - the average value of runoff. 
Error in determining the runoff is equal to (Kovalenko and Pivovarova 2000):

$$
\sigma_{0}=\frac{C_{v}}{\sqrt{N}}
$$

where: $C_{v}$ - the coefficient of runoff variation; $N$ - the number of years of observation.

The gradient criterion determines the minimum area per one station and is determined by physical and geographical conditions of the countryside. This criterion characterizes the reliability of information on the spatial and temporal changes in river runoff fluctuations. Positioning hydrological stations more frequently than required by this criterion is economically unviable, i.e. $F_{\text {grad }} \leq F_{\text {opt }}$.

The third criterion is the correlation criterion $F_{\text {corr }}$. Use of this criterion is due to the method of hydrological analogy when data of an unexplored body of water is obtained from the data of an object under study with similar hydrological and hydro-meteorological conditions of river runoff. The correlation criterion is defined as follows (Karasev 1968):

$$
F_{\text {corr }} \leq \frac{\sigma^{4}}{\alpha^{2} C_{v}^{2}},
$$

where: $\sigma$ - relative random error in determining the runoff for hydrometric data, in the first approximation, equal to $0.05 ; \alpha=\frac{1}{L_{0}} ; L_{0}$ - the correlation radius, i.e. the distance at which the spatial correlation function passes through zero (Rozhdestvensky and Chebotarev 1974).

The correlation criterion defines the upper limit of the calculated optimal area of hydrological stations, i.e. $F_{\text {opt }} \leq F_{\text {corr }}$.

The optimal area per one station should be in the following ranges:

$$
F_{\text {repr }}<F_{\text {grad }} \leq F_{\text {opt }} \leq F_{\text {corr }} .
$$

If the above relationship between the criteria is not met, it is recommended (Karasev 1968) $F_{\text {repr }}<F_{\text {corr }}<F_{\text {grad }}$ in relation to use $F_{\text {corr }}<F_{\text {opt }}<F_{\text {grad }}$. The optimal number of the regime of hydrological stations for the area is given by:

$$
N_{\text {opt }}=\frac{F}{F_{\text {opt }}},
$$

where: $F-$ the total land area.
Material for the research was the values of the long-term annual, maximum spring, minimum summer-autumn and winter minimum runoff of the 97 hydrological stations of Belarus for the period of instrumental observations. To evaluate the transformation of the river water regime caused by climatic fluctuations and anthropogenic impacts, the results of stationary water and climate observations made by the Republican Hydro-meteorological Center of the Ministry of Natural Resources of the Republic of Belarus were used, which were published in the proceedings of government inventories. The initial data received series of observations of air temperature, precipitation and humidity deficits from 1950 to 2009 for the 40 meteorological stations in Belarus, evenly situated on the study area. During the study the original series was divided into two periods: $1950-1984$ and 19852009. The boundary of the partition for the periods was due to the fact that in 1985 there was a noticeable change in the climatic conditions of the country.

In the statistical analysis of time series to identify trends in climate parameters, the chronological fluctuations and monthly charts of difference integral curves were used and to evaluate differences in the statistical parameters applied, Student and Fisher tests were used (Volchek 2002). To predict the change of water regime of Belarus' rivers, the method of hydrological calculation was adapted, and climate calculations based on the simultaneous solution of equations of heat and power and water balance were used (Mezentcev et al. 1980). The equation of the water balance of the river basin for a certain period of time is as follows:

$$
Y_{K}(I)=H(I)-Z(I)
$$

where: $Y_{K}(I)$ - the total climatic runoff, mm; $H(I)$ - the total resources of humidification, $\mathrm{mm}$; $Z(I)$ - evaporation, $\mathrm{mm} ; I$ - averaging interval.

Total evaporation is as follows:

$$
Z(I)=Z_{m}(I)\left[1+\left(\frac{\frac{Z_{m}(I)}{W_{H B}}+V(I)^{1-r(I)}}{\frac{X(I)+g(I)}{W_{H B}}+V(I)}\right)^{n(I)}\right]^{-\frac{1}{n(I)}},
$$

where: $Z_{m}(I)$ - the maximum evaporation, $\mathrm{mm}$; $W_{H B}$ - the smallest moisture content of the soil, mm; 
$V(I)=\frac{W(I)}{W_{H B}} \quad \begin{aligned} & \text {-relative humidity of soil at the begin- } \\ & \text { ning of the water budget period; } X(I)-\end{aligned}$ the amount of precipitation, $\mathrm{mm} ; g(I)$ - groundwater component of the water balance, $\mathrm{mm}$; $r(I)$ - parameter depending on the water-physical properties and mechanical composition of soil; $n(I)$ - the parameter that takes into account physical and geographical conditions of runoff.

The modelling of the water balance is implemented in a computer program and carried out in two stages. The first step is setting up the model of the river-equivalent, with similarities of the formation of the water regime of rivers. The second stage is a direct calculation of the water balance of the river under study (Volchek and Parfomuk 2007).

\section{Results and Discussion}

First of all, the optimal number of hydrological monitoring stations for the values of the annual runoff of Belarus was investigated. To find a representative criterion $F_{\text {repr }}$ a methodology based on the Student test is used. Studies have shown that a representative area per one hydrological station monitoring the quantities of the annual runoff for the territory of Belarus is $374 \mathrm{~km}^{2}$. The gradient criterion $F_{\text {grad }}$ was based on the annual average runoff of the studied rivers and runoff gradients. To find the parameters in the formula (1) maps of the coefficient of variation and average runoff were created. Thus, the calculated value of the gradient criterion for the territory of Belarus amounted to 1739 $\mathrm{km}^{2}$. The calculation of the correlation criterion $F_{\text {corr }}$ is based on finding the correlation radius $L_{0}$. To define it the spatial correlation function (SCF) of the annual runoff $r(l)$ was built, where $r$ - the simple correlation coefficient, $l$ - the distance between the stations (Fig. $1)$. The correlation radius for the territory of Belarus amounted to $688 \mathrm{~km}$, and the corresponding value of the correlation criterion $F_{\text {corr }}=1218 \mathrm{~km}^{2}$.

With the ratio $F_{\text {repr }}<F_{\text {corr }}<F_{\text {grad }}$, the optimal area per one hydrological station is determined from the relation $F_{\text {corr }}<F_{\text {opt }}<F_{\text {grad }}$.

If we start from the gradient criterion, the total number of stations for the runoff regime in Belarus is 119. If we start from the correlation criterion, then the optimal number of hydrological monitoring stations of the values of annual runoff is 170 .

Further research was conducted on extreme runoff: the maximum spring, the minimum summer- autumn and winter minimum. The maximum spring runoff representative test $F_{\text {repr }}$ is $969 \mathrm{~km}^{2}$, the value of the gradient criterion $F_{\text {grad }}$ was $3297 \mathrm{~km}^{2}$. The correlation radius in the construction of SCF for the maximum river runoff in Belarus is $1140 \mathrm{~km}$ (Fig. 1). The value of the correlation criterion $F_{\text {corr }}=97 \mathrm{~km}^{2}$. In the study of minimum types of runoff, the following results were obtained. For minimum summer-autumn runoff: $F_{\text {repr }}=363 \mathrm{~km}^{2}, F_{\text {grad }}=2812 \mathrm{~km}^{2}, F_{\text {corr }}=847$ $\mathrm{km}^{2}$. For minimum winter runoff, values of the representative, gradient and correlation criteria are 567, 2166 , and $5154 \mathrm{~km}^{2}$, respectively. SCF of the different runoff types are shown in Figure 1.

Values of the least and the largest number of stations observing the maximum and minimum runoff types are shown in Table 1. Today the number of stations existing in Belarus equals 122, and is sufficient to measure the maximum and minimum summer-autumn runoff. To measure the minimum winter runoff exceeds the required value of the maximum number of stations. The values of the smallest and the largest quantity of hydrological observation stations for maximum drain vary greatly in view of the large values of the coefficients of variation and runoff, included in the formulas used to calculate the correlation and gradient criteria. As for the annual values of river runoff in Belarus, the number of observation stations approaches the critical minimum level. Further reduction in hydrological stations on the territory of Belarus is unacceptable in view of determining the value of the average annual runoff in the hydrological and agronomic calculations, hydraulic engineering and other industries.

Consider the two parts of the runoff series: the time period prior to the current warming climate and intensive land reclamation (I) and the subsequent period after the adoption of the State Programme for the Development of Reclamation (II). To find the correlation criterion, SCF of the river runoff in Belarus for two periods were built, and the corresponding correlation radii were found (Table 2). Representative values, gradient and correlation criteria for the test series of the two parts are shown in Table 2.

Values of the fewest and the largest number of stations for different types of observations for two periods are shown in Table 3. The required minimum number of stations in the various types of runoff for the periods before and after global warming and the beginning of active human activities should be increased. The maximum number of stations required depending on the kind of runoff should be larger or 

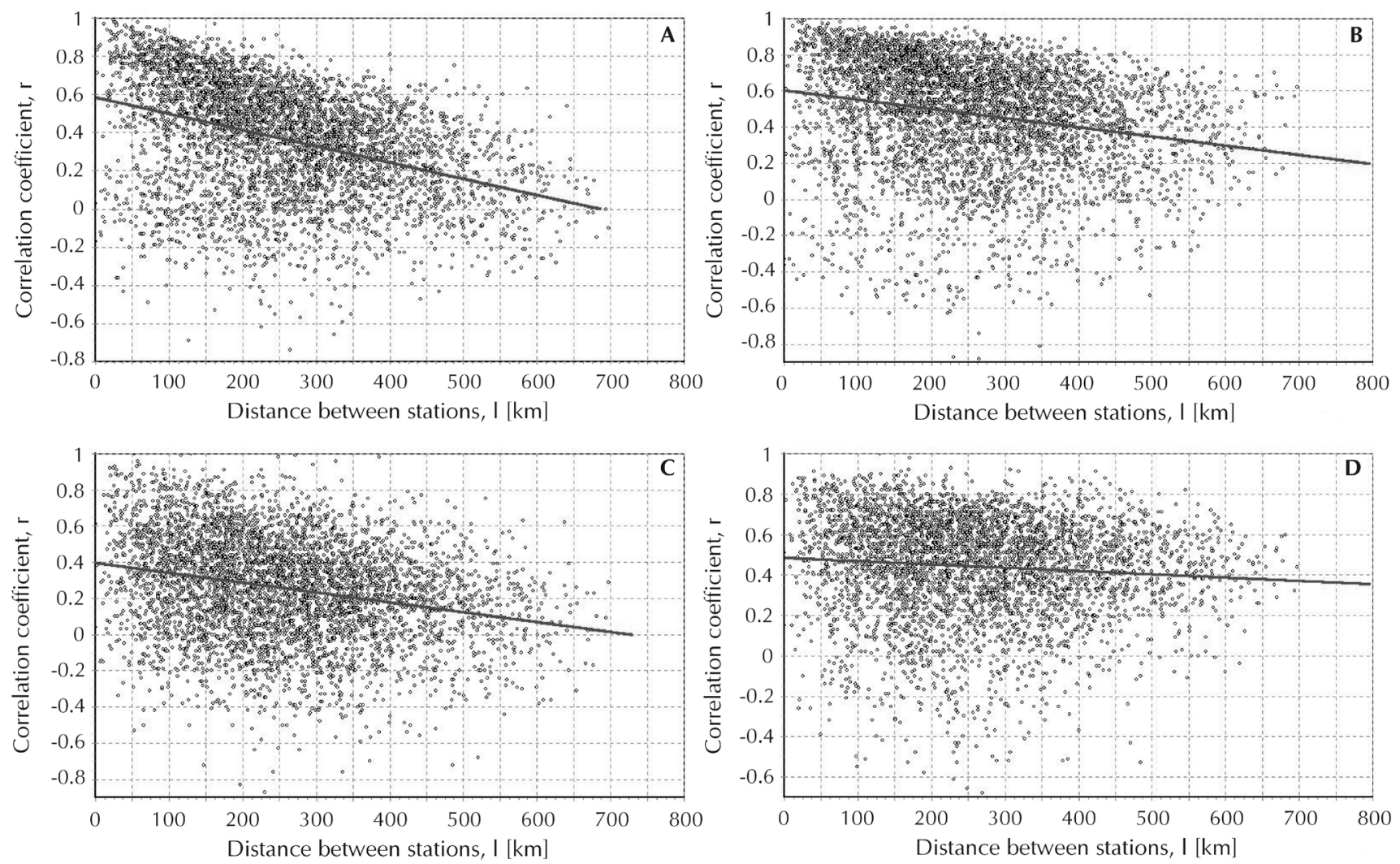

Fig. 1. Spatial correlation function (SCF) of the different runoff types: A - mean annual, B - maximum, C - minimum summer-autumn, $\mathrm{D}$ - minimum winter

smaller. The number of monitoring stations of the annual river runoff in Belarus should be large, though it is not much different from the existing number of hydrological stations in the country.

Furthermore, the optimal number of stations in low-water and high-water periods for the respective types of river runoff in Belarus was investigated. The values of correlation ranges for runoff in Belarus, as well as representative, gradient and correlation criteria for low-water and high-water periods are given in Table 4.

The values of the fewest and the largest number of stations in the various types of runoff for low-water and high-water periods are shown in Table 5. At various times the number of monitoring stations corresponds to the available quantity of almost all types of runoff. The only exceptions are low-water periods for the minimum winter runoff, which indicate the insufficient number of stations in the winter runoff in lowwater years.

The second stage of the research was to analyse the transformation of the climatic parameters. Series of observations (from 1985 to 2009) of air temperature, precipitation and humidity deficits have been extended to 2020 using a linear trend. It was found that the trend of annual mean air temperature is $0.7^{\circ} \mathrm{C}$ per 10 years, the average annual values of precipitation 20 $\mathrm{mm}$ per 10 years, and annual average humidity deficits $0.21 \mathrm{mb}$ per 10 years (the period of 1985-2009). During this time the intra-structure of the considered climatic parameters changed significantly, which is especially characteristic of January, July and September.

The next step was to analyse the possible changes in river runoff depending on the forecast climate change in 2020. As a result of research there can be traced quite a clear trend to possible changes in river runoff in the direction from the north-west to the south-east of the country (Fig. 2).

It is stated that the forecast trend of climatic parameters for the 2020 runoff for the basins of the Western Dvina and the Vilia will reduce by an average $5-10 \%$ compared to the present level. The annual runoff in the basins of the Neman and the Western Bug will not undergo significant changes in 2020. The 
Table 1. The least and the largest number of hydrological stations in Belarus

\begin{tabular}{ccccc}
\hline \multirow{2}{*}{$\begin{array}{c}\text { Number of hydrological } \\
\text { stations }\end{array}$} & Annual & Maximum & Minimum summer-autumn & Minimum winter \\
\cline { 2 - 5 } & 119 & 63 & 74 & 40 \\
\hline The smallest & 170 & 2138 & 245 & 96 \\
\hline The largest & & & \\
\hline
\end{tabular}

Table 2. Values of the criteria for the two-part series of river runoff

\begin{tabular}{|c|c|c|c|c|c|}
\hline \multirow[b]{2}{*}{ Period } & \multirow[b]{2}{*}{ Type of runoff } & \multirow[b]{2}{*}{$\begin{array}{c}\text { Correlation radius } L_{0} \\
{[\mathrm{~km}]}\end{array}$} & \multicolumn{3}{|c|}{ The values of the criteria per $\mathrm{km}^{2}$} \\
\hline & & & $F_{r e p r}$ & $F_{\text {grad }}$ & $F_{\text {corr }}$ \\
\hline \multirow{4}{*}{1} & Annual & 1185 & 1480 & 2574 & 4809 \\
\hline & Maximum & 1294 & 760 & 11682 & 92 \\
\hline & Minimum summer-autumn & 1372 & 1040 & 3375 & 2550 \\
\hline & Minimum winter & 4833 & 1290 & 1850 & 12405 \\
\hline \multirow{4}{*}{ II } & Annual & 657 & 363 & 1835 & 1425 \\
\hline & Maximum & 1248 & 969 & 4380 & 186 \\
\hline & Minimum summer-autumn & 685 & 374 & 3081 & 924 \\
\hline & Minimum winter & 2885 & 567 & 2710 & 3868 \\
\hline
\end{tabular}

Table 3. The least and the largest number of monitoring stations for the two-part series of river runoff

\begin{tabular}{cccc}
\hline \multirow{2}{*}{ Period } & Type of runoff & \multicolumn{2}{c}{ Number of hydrological stations } \\
\cline { 2 - 4 } & Annual & The least & The largest \\
\hline & Maximum & 43 & 81 \\
\cline { 2 - 4 } & Minimum summer-autumn & 18 & 2248 \\
\hline & Minimum winter & 62 & 81 \\
\hline & Annual & 17 & 112 \\
\hline II & Maximum & 113 & 146 \\
\cline { 2 - 4 } & Minimum summer-autumn & 47 & 1114 \\
\cline { 2 - 4 } & Minimum winter & 67 & 225 \\
\hline
\end{tabular}

Table 4. Values of the criteria for low-water and high-water periods

\begin{tabular}{|c|c|c|c|c|c|}
\hline \multirow[b]{2}{*}{ Period } & \multirow[b]{2}{*}{ Type of runoff } & \multirow[b]{2}{*}{$\begin{array}{c}\text { Correlation radius } L_{0} \\
{[\mathrm{~km}]}\end{array}$} & \multicolumn{3}{|c|}{ The values of the criteria per $\mathrm{km}^{2}$} \\
\hline & & & $F_{r e p r}$ & $F_{g r a d}$ & $F_{\text {corr }}$ \\
\hline \multirow{4}{*}{ Low-water } & Annual & 569 & 374 & 2772 & 2565 \\
\hline & Maximum & 1013 & 969 & 4470 & 182 \\
\hline & Minimum summer-autumn & 495 & 340 & 5075 & 1033 \\
\hline & Minimum winter & 470 & 492 & 1694 & 750 \\
\hline \multirow{4}{*}{ High-water } & Annual & 453 & 410 & 3492 & 857 \\
\hline & Maximum & 609 & 969 & 23201 & 159 \\
\hline & Minimum summer-autumn & 530 & 313 & 2303 & 607 \\
\hline & Minimum winter & 1264 & 363 & 4554 & 1668 \\
\hline
\end{tabular}


Table 5. The least and the largest number of hydrological stations for low-water and high-water periods

\begin{tabular}{|c|c|c|c|}
\hline \multirow{2}{*}{ Period } & \multirow{2}{*}{ Type of runoff } & \multicolumn{2}{|c|}{ Number of hydrological stations } \\
\hline & & The least & The largest \\
\hline \multirow{4}{*}{ Low-water } & Annual & 75 & 81 \\
\hline & Maximum & 46 & 1138 \\
\hline & Minimum summer-autumn & 41 & 201 \\
\hline & Minimum winter & 123 & 277 \\
\hline \multirow{4}{*}{ High-water } & Annual & 59 & 242 \\
\hline & Maximum & 9 & 1307 \\
\hline & Minimum summer-autumn & 90 & 342 \\
\hline & Minimum winter & 46 & 124 \\
\hline
\end{tabular}

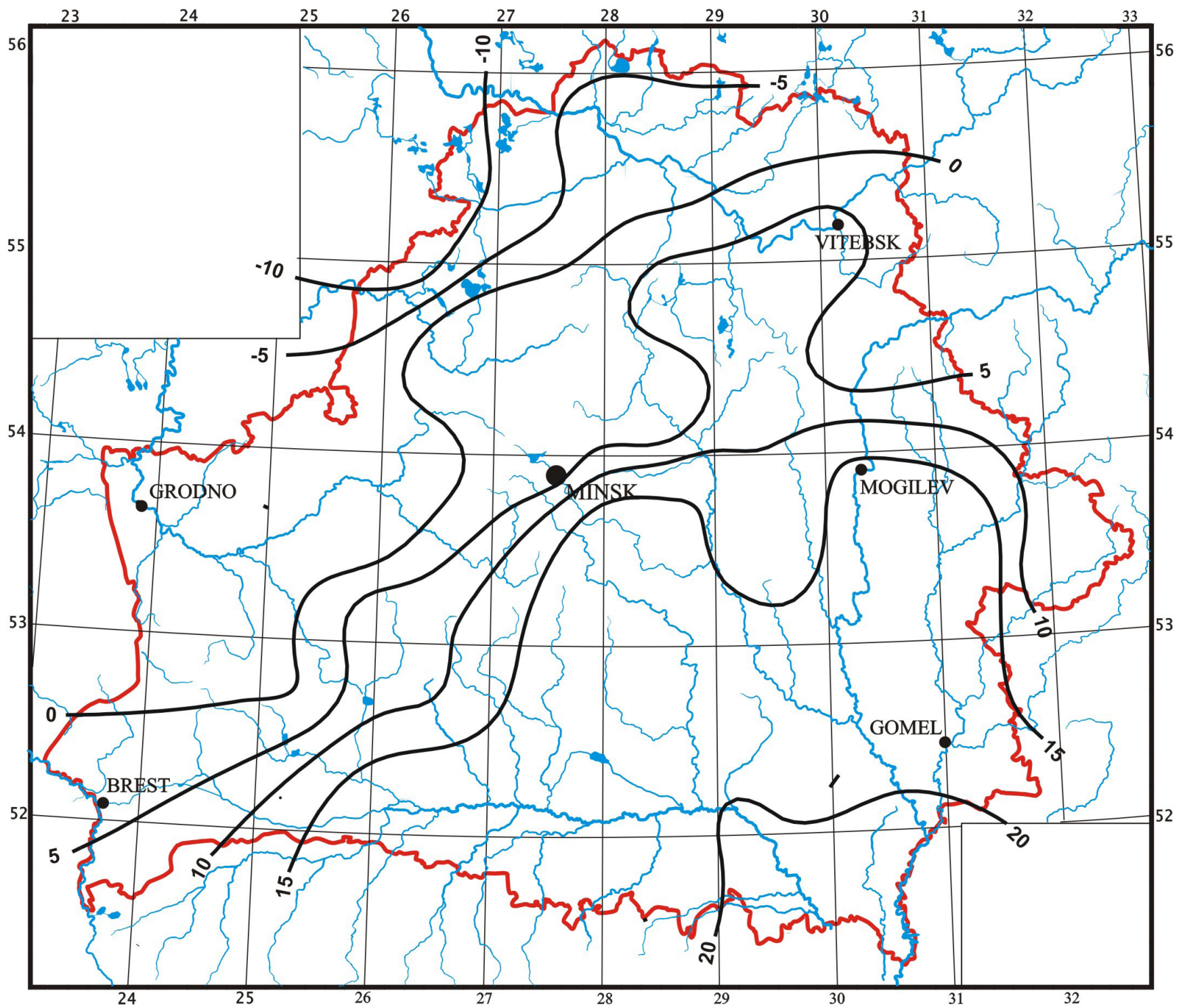

Fig. 2. Possible changes in river runoff as a function of forecasted climate change in 2020 , as $\%$ of 2009 
largest increase in average annual runoff of the rivers may occur in the Dnieper and the Pripyat basins and can reach $20 \%$ of the watershed in relation to 2009 . To study possible intra-runoff transformation in 2020, the most significant change in monthly values of water consumption in March-June was pointed out.

\section{Conclusions}

The optimal number of hydrological monitoring stations for the annual values, the maximum spring, the minimum summer-autumn and the minimum winter river runoff in Belarus is determined. The research on optimization of the hydrological network of Belarus led to a conclusion about the optimum number of hydrological stations in the country, though in the case of observing the values of the annual runoff, the number of the existing plants is the minimum necessary and a reduction in their number is inadmissible. Studies of the effect of climate warming and the beginning of active human activities have shown the need to increase the minimum required number of hydrological stations. In the study of lowwater and high-water periods and different types of river runoff in Belarus, the need was highlighted to increase the number of observation stations for the winter runoff in low-water years.

On the basis of trends in air temperature, precipitation and humidity variations from 1985 to 2009 the forecasts of these parameters are prepared until 2020. Given the changes in climatic parameters, the possible changes in the water regime of the rivers in the future are investigated. The results demand further investigation in terms of the analysis of forecast errors and the possible development of compensatory measures to reduce the impacts of climate change and the water regime of the Republic of Belarus.

\section{References}

Bedritskiy A.I., Blinov V.G., Gershinkova D.A., Golitsyn G.S., Dymnikov V.P., Izrael A., Katzov V.M., Kotlyakov V.M., Meleshko V.P., Osipov V.I., Semenov S.M. (eds), 2008, Otsenochnyi doklad ob izmenenakh klimata i ikh posledstviakh na territorii Rossiiskoi Federacii. Tom 2: Posledstvia uzmenenii klimata (Assessment report on climate change and its consequences on the territory of the Russian Federation. Vol. 2: Consequences of climate change), Rosgidromet, Moscow, p. 288 (in Russian).

Karasev I. F., 1968, O principakh razmeshchenia i perspektivakh razvitia gidrologicheskoi seti (On the principles of placement and prospects of hydrological network development), Trudy GGI 164: 3-36 (in Russian).

Kovalenko V.V., Pivovarova I.I., 2000, Optimizacia rezhimnoi gidrologicheskoi seti na osnove stokhasticheskoi modeli formirovania rechnogo stoka (Optimization of the regime of the hydrological network based on a stochastic model of river runoff), Izd. RGGMU, Sankt-Petersburg, p. 43 (in Russian).

Loginov V.F. (ed.), 2003, Prognoz izmenenia okruzhaiushchei sredy Belarusi na 2010-2020 gg (Forecast of the environmental change of Belarus for 2010-2020), Minsktipproekt, Minsk, p. 180 (in Belarusian).

Mezentcev V.S., Belonenko G.V, Karnatsevich I.V., Loskutov V.V., 1980, Gidrologicheskie raschioty v meliorativnykh celakh (Hydrologic calculations for land reclamation purposes), Izd. OmGAU, Omsk, p. 80 (in Russian).

Rozhdestvensky A.V., Chebotarev A.I., 1974, Statisticheskie metody v gidrologii (Statistical methods in hydrology), Gidrometeoizdat., Leningrad, p. 424 (in Russian).

Volchek A.A., 2002, Matematicheskie modeli v prirodopolzovanii (Mathematical models in environmental management), Izd. BGU, Minsk, p. 282 (in Belorussian).

Volchek A.A., Parfomuk S.I., 2007, Ocenka transformacii vodnogo rezhima malykh rek Belorusskogo Polesia pod vozdeistvem prirodnykh i antropogennykh faktorov (na primere r. Jaselda) (Evaluation of water regime transformation in minor rivers of Belarusian Polesye under the influence of natural and anthropogenic factors based on the example of the Yaselda River), Vodnoe Khozaistvo Rossii 1: 50-62 (in Russian). 